\title{
Termination of pregnancy: Cultural practices, the Choice on Termination of Pregnancy Act and the constitutional rights of children
}

\author{
D J McQuoid-Mason, BComm, LLB, LLM, PhD \\ Centre for Socio-Legal Studies, University of KwaZulu-Natal, Durban, South Africa
}

Corresponding author: D J McQuoid-Mason (mcquoidm@ukzn.ac.za)

\begin{abstract}
The cultural practice of ukuthwala, the abduction for marriage of young girls, violates their constitutional rights and contravenes the Children's and Sexual Offences Act. The provisions of the Choice Act for the third trimester of pregnancy are more onerous than the former Abortion Act and violate the constitutional rights of girls and women who face a serious threat to their physical or mental health or have been raped or subjected to incest. The Choice Act should be amended accordingly. Until it is amended, healthcare practitioners should use the constitutional 'best interests of the child' principle as interpreted by the Children's Act when deciding whether or not to terminate the pregnancy of a child in the third trimester.
\end{abstract}

S Afr Med J 2018;108(9):721-723. DOI:10.7196/SAMJ.2018.v108i9.13289

Should a young girl fall pregnant under the practice of $u$ kuthwala, the abduction for marriage of young girls ${ }^{[1]}$ and is denied an abortion by the hospital services when she is $>20$ weeks pregnant, the following issues must be considered: (i) What does the Constitution ${ }^{[2]}$ say about healthcare and reproductive health for children?; (ii) Does ukuthwala violate the Constitution?; (iii) Does ukuthwala violate the Sexual Offences Act ${ }^{[3]}$ and the Children's Act?; ${ }^{[4]}$ and (iv) Do the restrictive third-trimester grounds for termination of pregnancy under the Choice on Termination of Pregnancy Act ${ }^{[5]}$ violate the constitutional rights of children?

\section{The Constitution, healthcare and} reproductive healthcare for chilldren

The Constitution ${ }^{[2]}$ provides that every child has the right to basic healthcare services, unlike adults, who only have the right of access to healthcare services, including reproductive healthcare. Therefore, while the State must make healthcare available in its facilities, adult patients must find their own way there. However, for children who are not in the care of their parents, the State must assist them to reach the relevant healthcare facility. ${ }^{[6]}$ Such children '.. have a direct and immediate claim on the State for the fulfilment of their socioeconomic rights. ${ }^{\text {[7] }}$

The Constitution does not mention healthcare services that include reproductive healthcare, as is the case with the general right of access to healthcare. However, the Constitution was not intended to provide children with lesser healthcare services than adults and should not be interpreted restrictively. The Constitutional Court has held that the constitutional provisions dealing specifically with children's rights do not limit their other rights in the Constitution, ${ }^{[8]}$ which states that 'a child's best interests are of paramount importance in every matter concerning the child'. Therefore, if the pregnancy of a child is likely to cause her severe psychological or physical injury but does not threaten her life, her request for a termination of pregnancy in the third trimester should be regarded as requiring 'basic healthcare'. Children's rights, as for everyone else, may only be limited if this is reasonable and justifiable as provided for in the Constitution. ${ }^{[9]}$
Does the culltural practice of

\section{ukuthwala violate the Constitution?}

The practice of $u$ kuthwala has been described as a 'mock abduction' or an 'irregular proposal' to achieve a customary law marriage. ${ }^{[1]}$ However, it has caused widespread abuse of children. In 2009, it was reported that in the Eastern Cape Province, under the pretext of the customary practice of ukuthwala, young girls were abducted, some with the consent of their parents, and compelled to leave school to 'marry' older men. Some men were HIV-positive and wanted to be 'cured' by having sex with a virgin. Many of the girls were infected with HIV and impregnated at an early age. They were also denied their other rights under the Constitution, ${ }^{[2]}$ such as being detained against their will in guarded huts and forced to have sex with their 'husbands', or being beaten and humiliated when trying to escape. ${ }^{[10]}$

The Constitution ${ }^{[2]}$ provides that everyone may participate in the cultural life of their choice but not in a manner inconsistent with any provision of the Constitution. Thus, ukuthwala may only be practised and enjoyed if not in conflict with the Constitution. However, judging from these reports, it violates many of the constitutional rights of young abducted girls and contravenes the general provision that the 'child's best interests are of paramount importance'. The constitutional rights of young girls violated by the practice of ukuthwala have been described and include: (i) equality, and not to be unfairly discriminated against; (ii) dignity, and to have their dignity respected and protected; (iii) freedom and security of the person; (iv) bodily and psychological integrity and security and control over their bodies, including the right to make decisions concerning reproduction; $(v)$ not to be subjected to slavery, servitude or forced labour; and $(v i)$ to live in an environment that is not harmful to their health or well-being, and the right to basic education. ${ }^{[10]}$

Does the practice of $u k u t h w a l a$ violate the Sexual Offences Act and the Children's Act?

The Criminal Law (Sexual Offences and Related Matters) Amendment $\mathrm{Act}^{\left[{ }^{3]}\right.}$ (Sexual Offences Act) repealed the common law offences of 
rape and indecent assault and replaced these with a new definition of rape, consisting of sexual penetration of a person without their consent. The Act also created the new offences of sexual assault and sexual exploitation of children. The practice of ukuthwala violates all these provisions. Individuals, such as doctors who have treated victims of sexual abuse, have a duty to report it to the authorities. Failure to report may only be justified by a doctor on very limited grounds, e.g. that it was not in the 'best interests' of the child, ${ }^{[11]}$ although this has not yet been tested in the courts.

The practice of ukuthwala violates the principle of the best interests of the child. Although the principle is not explained in the Constitution, the factors influencing it are referred to in the Children's Act, ${ }^{[4]}$ which provides useful guidelines for healthcare practitioners to make decisions based on the best interests of the child. The Act provides that when determining the best interests of the child the following factors should be taken into account: (i) the nature of the relationship between 'the child and any other caregiver or person relevant in those circumstances'; (ii) the child's age, maturity and stage of development, gender, background and any other relevant characteristic of the child; (iii) the child's physical and emotional security and his or her intellectual, emotional, social and cultural development; (iv) the need to protect children from any physical or psychological harm that may be caused by subjecting them to maltreatment, abuse, neglect, exploitation or degradation, or exposing them to violence or exploitation or other harmful behaviour; and $(v)$ deciding which action would avoid or minimise further legal or administrative proceedings in relation to the child. ${ }^{[4]}$ Similar duties of reporting, such as those in the Sexual Offences Act, ${ }^{[3]}$ exist under the Children's Act, ${ }^{[4]}$ which also require child sexual abuse to be reported. The last factor regarding avoiding or minimising legal or administrative proceedings may have some bearing in determining whether or not it is in the best interests of the child to report the sexual abuse.

\section{Do the restrictive third-trimester grounds for termination of pregnancy under the Choice on Termination of Pregnancy Act violate the constitutional rights of children?} Purpose of the Choice on Termination of Pregnancy Act The Choice on Termination of Pregnancy Act ${ }^{[5]}$ (Choice Act) 'repeals the restrictive and inaccessible provisions of the Abortion and Sterilization Act, ... promotes reproductive rights and extends freedom of choice by affording every woman the right to choose whether to have an early, safe and legal termination of pregnancy according to her individual beliefs'. Therefore, one must consider the following: (i) whether the third-trimester provisions of the Choice Act are less restrictive than those in the repealed Abortion and Sterilization Act ${ }^{[12]}$ (Abortion Act); and (ii) whether the Choice Act provisions make termination of pregnancy more accessible than under the repealed Act. If the Choice Act is more restrictive and makes terminations less accessible in the third trimester because they exclude women who have been subjected to rape or incest from having an abortion after the 20th week of gestation, are these provisions unconstitutional? ${ }^{[13]}$

Grounds for termination of pregnancy during the second and third trimesters under the Choice on Termination of Pregnancy Act

The Choice Act ${ }^{[5]}$ provides that termination of pregnancy after 20 weeks may only be performed if a doctor, after consultation with another doctor (or a registered midwife who has completed the prescribed training course), believes that the continued pregnancy: (i) would endanger the woman's life; (ii) would result in severe malformation of the fetus; or (iii) would result in a risk of injury to the fetus. In the case of a severely mentally disabled woman or one in a state of continuous unconsciousness, the grounds are the same, except for the consent provisions, which require that the two medical practitioners (or a medical practitioner and a registered midwife who has completed the prescribed training course) may consent to her termination of pregnancy after consulting her natural guardian, spouse, legal guardian or curator. However, the termination of pregnancy may not be denied if the persons consulted refuse consent. The grounds in the third trimester after 20 weeks of pregnancy are more restrictive than those in the 13th - 20th week, i.e.: (i) there is a risk of injury to the woman's mental or physical health; (ii) there is a substantial risk that the fetus would suffer from a severe physical or mental abnormality; (iii) the pregnancy resulted from rape or incest; or (iv) the continued pregnancy would significantly affect the social or economic circumstances of the woman. Pregnant children of any age may consent to termination of pregnancy without the knowledge or consent of their parents or guardians, provided they are able to give an informed consent based on the knowledge, appreciation and consent criteria required by the common law, ${ }^{[14]}$ and understand the information that must be given according to the National Health Act. ${ }^{[15]}$

\section{Grounds for termination of pregnancy under the former Abortion and Sterilization Act}

The former Abortion Act ${ }^{[11]}$ provided that in all instances, 2 doctors other than the doctor procuring the abortion had to certify that: (i) the continued pregnancy endangered the woman's life; (ii) the continued pregnancy was a serious threat to the woman's physical or mental health and will cause permanent damage; (iii) there was a serious risk that the child would suffer a physical or mental defect so that he/she would be irreparably seriously handicapped; (iv) the fetus has allegedly been conceived as a result of rape or incest; or $(v)$ the fetus was conceived in illegitimate intercourse with a woman who was, owing to a permanent mental handicap or defect, unable to comprehend the consequential implications of or bear the parental responsibility for its consequences. Where the pregnancy was alleged to have been as a result of rape or incest, a certificate had to be issued by the local magistrate who had to investigate the matter and decide, on a balance of probabilities, that such an offence had indeed been committed. Furthermore, the woman had to submit an affidavit stating that the pregnancy was due to the alleged rape or incest.

\section{Are third-trimester restrictions in the Choice on Termination of Pregnancy Act unconstitutional?}

Under the Abortion Act ${ }^{[12]}$ there were no time limits for when abortions on the listed grounds could be procured, i.e. a trimester system was not recognised. An abortion could be procured at any time, provided the grounds for justifying it were satisfied. During the first 20 weeks of the pregnancy the grounds for termination of pregnancy in terms of the Abortion Act were stricter than those under the Choice Act. ${ }^{[5]}$ However, after the 20th week, the reverse is true, because some of the grounds that existed under the Abortion Act are not available to pregnant women under the Choice Act once the 20th week of pregnancy begins. For instance, under the Abortion Act, a termination could be done where there was a serious threat to the woman's physical and mental health or where the fetus was conceived as a result of rape or incest. The third-trimester restrictions contradict the purpose of the Choice Act, but also violate a pregnant 
woman's constitutional right to bodily and psychological integrity and access to reproductive healthcare. ${ }^{[12]}$

The restrictions in the Choice $\mathrm{Act}^{[5]}$ during the third trimester place an 'undue burden' on women who have been subjected to rape or incest and who can only seek assistance to terminate a pregnancy after 20 weeks of gestation. ${ }^{[13]}$ The Choice Act places the same burden (even if they are not aware of it) on severely mentally disabled or unconscious women. Mentally competent women may thus experience severe psychological trauma if compelled to carry their pregnancies to term. It is also likely to expose children conceived by rape or incest to similar trauma should the circumstances of their conception become known. Therefore, the limitations to a termination of pregnancy after the 20th week of gestation in the Choice Act that deny abortions to women who have been subjected to rape or incest are unconstitutional. ${ }^{[13]}$ The grounds for termination in the third trimester should be expanded to include a serious threat to the woman's physical or mental health and where the fetus has been conceived as a result of rape or incest, without the onerous conditions that applied under the Abortion Act. ${ }^{[13]}$

Consulting doctors and midwives may circumvent the Choice Act's ${ }^{[5]}$ third-trimester limitations if the pregnant girl or woman who has been raped or subjected to incest threatens suicide or will procure a backstreet abortion, as this could justify their being of the opinion that the continuing pregnancy would 'endanger' the patient's life. Where a pregnant child does not make such threats, the consulting healthcare practitioners may still use the constitutional principle of the best interests of the child because it is 'of paramount importance in every matter concerning the child. ${ }^{[2]}$ The Children's Act ${ }^{[4]}$ provides useful guidelines for determining whether the principle of best interests should apply to the restrictions in the third trimester of the
Choice Act. ${ }^{[5]}$ However, these mechanisms are somewhat artificial and the Act should be amended to include, as grounds in the third trimester, a serious threat to the physical or mental health of the pregnant female or that she has been raped or the victim of incest. This is because the third-trimester limitations are too restrictive of the constitutional right to bodily and psychological integrity and reproductive health of girl children and women and also because the Choice Act should provide clear guidelines for consulting doctors and midwives that are in line with the Constitution.

\author{
Acknowledgements. None. \\ Author contributions. Sole author. \\ Funding. National Research Foundation. \\ Conflicts of interest. None.
}
1. Bennett TW. Customary Law in South Africa. Cape Town: Juta, 2004:212.
2. Constitution of the Republic of South Africa, 1996.
3. South Africa. Criminal Law (Sexual Offences and Related Matters) Amendment Act No. 32 of 2007. 4. South Africa. Children's Act No. 38 of 2005.
5. South Africa. Choice on Termination of Pregnancy Act No. 92 of 1996
6. Centre for Child Law v Minister of Home Affairs 2005 (6) SA 50 (T).
7. Currie I, de Waal J. The Bill of Rights Handbook. 6th ed. Cape Town: Juta, 2013:612.
7. Currie I, de Waal J. The Bill of Rights Handbook. 6th ed. Cape Town: Juta, 2013:612.
8. Minister of Welfare and Population Development v Fitzpatrick 2000 (3) SA 422 (CC).
9. De Reuck v Director of Public Prosecutions, Witwatersrand Local Division 2004 (1) SA 406 (CC).
9. De Reuck v Director of Public Prosecutions, Witwatersrand Local Division 2004 (1) SA 406 (CC).
10. McQuoid-Mason DJ. The practice of ukuthwala, the Constitution and the Criminal Law (Sexual McQuoid-Mason DJ. The practice of ukuthwala, the Constitution and
Offences and Related Matters) Amendment Act. Obiter 2009;30:716-723.
11. McQuoid-Mason D. Mandatory reporting of sexual abuse under the Sexual Offences Act and the best interests of the child?. S Afr J Bioethics Law 2011;4(2):74-78.
12. South Africa. Abortion and Sterilization Act No. 2 of 1975
13. McQuoid-Mason DJ. Are the restrictive provisions of sections 2(1)(c) and 5(5)(b) of the Choice on Termination of Pregnancy Act 92 of 1996 unconstitutional? J Jur Sc 2006;31(1):121-133.
14. Castell v De Greef 1994 (4) SA 408 (C).
15. South Africa. National Health Act No. 61 of 2003

Accepted 12 April 2018. 